\title{
Experimental Investigation of Using Nano Fluid to Improve Productivity Index on Enhancing Oil Recovery
}

\author{
Majid Sajjadian', Valiahmad Sajjadian², Ali Akbar Daya ${ }^{3}$ \\ ${ }^{1,2}$ Department of chemistry engineering, Marvdasht Branch, Islamic Azad University Marvdasht, Iran \\ ${ }^{3}$ :Department of Mining Engineering, University of Sistan and Baluchestan
}

\begin{abstract}
As many oil fields go into their final stage of production, novel technologies are necessary in order to maintain the production and increase the recovery of hydrocarbons. Therefore, advanced technology like Nanotechnology should be coming to overcome the problem of low recovery from reservoirs. Nano fluids were injected as a tertiary recovery method following a secondary water flooding. The experiments were performed at ambient conditions. Interfacial tensions and contact angles were measured in order to help explain the underlying mechanisms behind the increased recovery.

In this research paper, the effect of silica nano and carbon nano particles on the wettability alteration in one of the Iran Sand Stone reservoir is mentioned. The results obtained from experiments show that these nano particles are suitable enhanced oil recovery (E.O.R) agents in water wet sand stone formations. Silica nano and carbon nano particles demonstrated same results in the wettability alteration of core plug. It was observed that the oil recovery increased by $5 \%$ when $0.05 \mathrm{wt}$. \% Sio $\mathrm{S}_{2}$ nano fluid was injected into the core sample in a tertiary mode.
\end{abstract}

Keywords: Nanoparticles, Contact Angle Test, Enhanced oil recovery

\section{INTRODUCTION}

The demand for energy is expected to increase around 50\% to60\% in the next 2-3 decades. According to a study by the US Department of Energy, the predicted global energy consumption will be around 700 Quadrillion British thermal units by 2030 [1]. Renewables, from wind, solar, small hydroand geothermal, is expected to grow at over seven per cent per year, often as a result of government support and incentives.

They certainly hold promise, but globally their share of thenergy mix will still be less than three per cent by 2035, given their low initial base. Both the share of biomass and nuclear remain at steady levels throughout the period from 2010 to2035, at around dnine percent and just below six per cent respectively. It is clear that fossil fuels will continue to play the dominant role in meeting demand, although their overall share will fall from 82 to 80 per cent. Throughout most of this period, oil will remain the energy source with the largest share, although its overall share declines from 33 to 27 per cent. [3].

Unless, revolutionary new sources of energy have been industrialized, yet it appears that we are going to be reliant on hydrocarbons for the foreseeable future [4].

Accordingly, meeting the World's growing energy demand will be a major challenge in the coming decades and will only be possible with revolutionary breakthroughs in the oil and gas industry. Breakthroughs in Nanotechnology have the potential to move the industry beyond the current alternatives for energy supply by introducing technologies that are more efficient and more environmentally sound [5]. The fast growth of worldwide demand for oil can be met effectively in only two ways: by finding new hydrocarbon resources or by enhancing the oil recovery of available reservoirs. However, the rate of new oilfield discoveries is declining, and most of the producing oilfields are in the late stages of production. The importance of improving oil production efficiency by enhanced oil recovery (EOR) techniques is highly acknowledged because in many of the world's reservoirs about two thirds of the oil in place cannot be recovered by conventional production methods [6]. 
Nanotechnology brings new and different capabilities into upstream E\&P. the industry desires strong, stable, friction resistant, and corrosion combatant materials in virtually all of its operations and processes (e.g. pipes, casing, drill stings, production tubings, and drill bits). These requirements are more favorably addressed with a bottom-up approach for material design and fabrication. Also, it is hoped that by employing nanofabricated particles in drilling, completion, stimulation, and injection fluids, one can drill faster, prevent or remove near wellbore damage, mine hydraulic fractures, plug water thief zones, reduce water flood fingering, encourage or enhance oil production, and prevent water breakthroughs. The industry looks also to capitalize on a new set of high-pressure/hightemperature (HP/HT) small-scale sensors that are disposable and more reliable and economical than their predecessors. It is hoped that this may soon lead to the development and development of sensing and intervention devices that can help delineate the water flood front, identify bypass oil, and map super permeability zones in-situ in the underground. The capabilities become limitless with the possibility of having functionalized molecular agents that illuminate the reservoir and intervene to rectify adverse transport conditions in the medium. The prospect of nanodevices in upstream E\&P ranges from mapping he extent of the asset to moving ahead of the drill bit to pre-identify trouble regimes [7]-[8].

Using other metal NPs can also be a good option in EOR. Recently, studies have explored the potential of $\mathrm{Al}_{2} \mathrm{O}_{3}, \mathrm{MgO}$ and $\mathrm{Fe}_{2} \mathrm{O}_{3}$ in addition to $\mathrm{SiO}_{2}$ nanoparticles. The results showed that some combinations have yielded better results than $\mathrm{SiO}_{2}$. Based on the current knowledge, it is expected that both chemical EOR and specifically micellar flooding will make huge benefits from nanotechnology and nanoemulsion in particular in the future [9]. Adding nanoparticles to fluids may significantly benefit enhanced oil recovery and improve well drilling, such as changing the properties ofthe fluid, wettability alternation of rocks, advanced drag reduction, strengthening sand consolidation, reducing the interfacial tension and increasing the mobility of the capillary-trapped oil [10].

In the past decadeto date, most investigations have shown that nanoparticles (NPs) offer promise for future enhanced oil recovery (EOR) processes where silica-based NPs have been most commonly used. Although the oil displacement mechanism with NPs is not yet clearly understood, the nanotechnology is now chosen as an alternative method to unlock the remaining oil resources and applied as a new enhanced oil recovery (EOR) method in the last decade [11-13]

The objective of this study is to investigate the potential of nanoparticles in water flooding for Enhanced oil recovery. This paper presents the effect of two different types of nano particles including $\mathrm{SiO}_{2}$ and carbon nano particles on the wettability of one of the Iran sand stone reservoir. The experimental procedures and impact of these nano particles on the alteration of wettability are mentioned. Core flooding experiments were conducted to investigate the effect of $\mathrm{SiO}_{2}$ nanoparticles on oil recovery during a tertiary recovery process.

\section{NANOPARTICles Materials}

A nano fluid is dispersion where small sized solid particles are suspended in a carrying fluid, usually water. A nanoparticle is typically between $1 \mathrm{~nm}$ and $100 \mathrm{~nm}$. Their size is much smaller than rock pore channels, meaning nanoparticles can easily penetrate through the reservoir rock without much retention [14].

Nano fluids can be designed with a wide variety of properties. Two of the main characteristics of nanoparticles is widely different from other EOR agents and can change the properties drastically; Firstly, their surface area to volume ratio is higher compared to similar material in a larger scale. This can enhance strength, electrical properties and make materials more chemical reactive. The overall effect is that less amount of NPs are needed compared to other chemicals like surfactants to achieve the same functions. In addition, quantum effects can affect the optical, electrical and magnetic behavior of the material. [15]

\subsection{SiO}

In many studies performed on nanouids for EOR an inorganic ceramic material composed of silica dioxide ( $\mathrm{SiO} 2)$ is used as nanoparticle. Some of the advantages with silica nanoparticles, apart from being cheap and easy accessible, is that they offer: (i) increased sedimentation stability as surface forces counter balance the gravity force; (ii) thermal, stress-strain and rheological properties can be tailored fora certain purpose during production by changing size, shape and surface chemistry of the nanoparticles and (iii) the chemical properties of nanoparticles can easily be controlled by surface coating substances. 


\subsection{Carbon Nano Particles}

Carbon nanoparticles represent a unique class of nano materials that are generally synthesized though a hydrothermal treatment process. Analogous to their well known cousins, fullerenes and carbon nanotubes, carbon nanoparticles exhibit interesting optical (and electrical) properties that may be exploited in applications such as optoelectronics, chemical sensing, biological labeling, and in this instance the upstream oil and gas.

\section{Mechanism the EFFect OF NANOPARTICles FOR InCREASED ENHANCED OIL RECOVERY (EOR)}

Several different EOR mechanisms for nano fluid are proposed and studied. Well established concepts of wettability alteration and interfacial tension reduction are not sufficient to fully explain the increased recovery seen. An overview of the potential EOR mechanisms will be given here.

\subsection{Structural Disjoining Pressure}

One of the most prominent mechanisms is the disjoining pressure. Investigations performed by Wasan and Nikolov(2003), Chengara et al. (2004), Wasan et al. (2011) and Mcelfresh et al. (2012) has revealed that the nanoparticles present in the three phase region between oil, water and rock tend to force themselves in between the discontinuous phase and the solid rock surface. The nanoparticles are creating a wedge like structure which works to separate the formation fluid (oil) from the pore wall and enhances the spreading behavior of the nano fluid. [16-18]

When an oil/liquid drop dispersed in an aqueous nano fluid approaches a smooth, hydrophilic solid surface, nanoparticles will assemble themselves in a solid-like ordering at the three-phase contact region, show Figure - 2. This assembly becomes more disordered and fluid-like towards the bulk phase. Studies have shown that the pressure arising from such an ordering in the confined region will enhance the spreading behavior of nano fluids.[19]

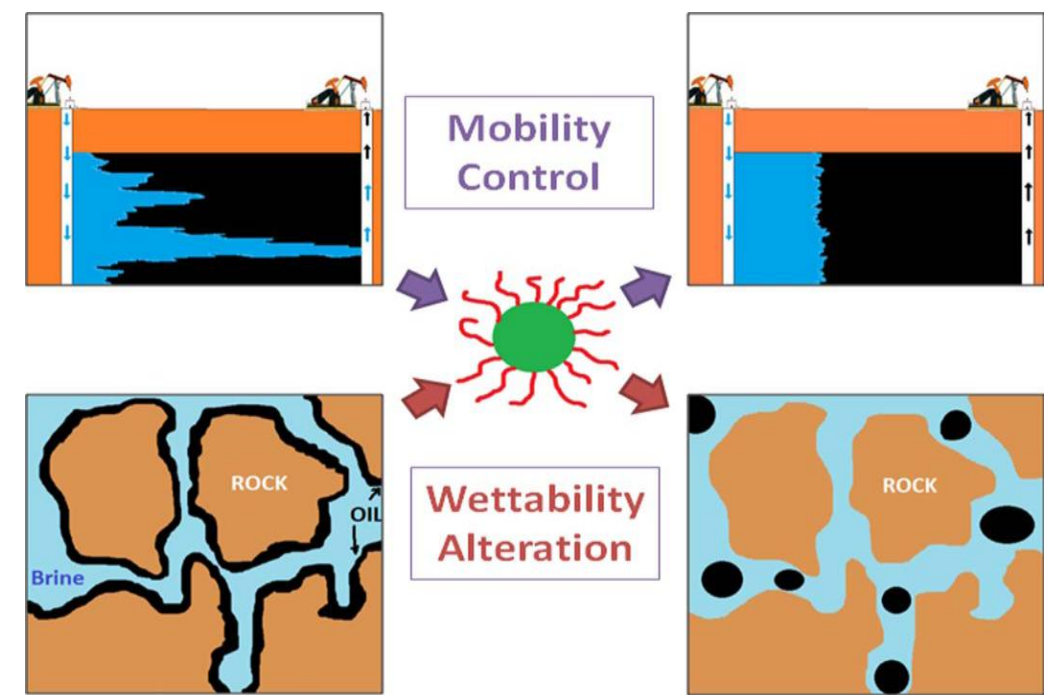

Figure1. Schematic for the application of PNPs in EOR through mobility control and wettability alteration[2]

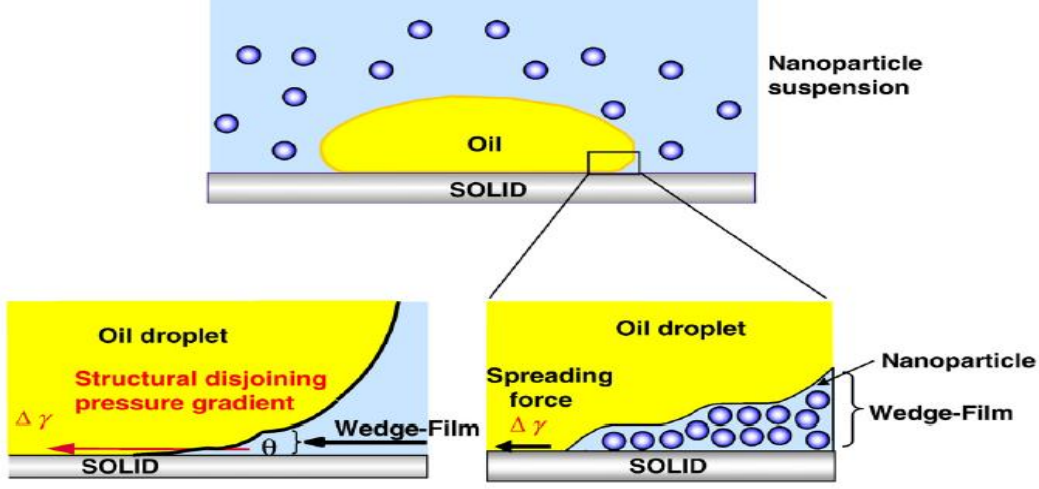

Figure2. Nanoparticles establishing a wedge film, resulting in a structural Disjoining pressure.[16] 
The particles that are present in the three-phase contact region will tend to form a wedge-like structure and force themselves in between the discontinuous phase and the solid rock surface. Particles present in the bulk fluid will apply a pressure that forces the particles in the wedge structure forward. This applied force is called the structural disjoining pressure, or film tension gradient $(\Delta \gamma)$.

The driving forces behind this phenomenon are electrostatic repulsion (where equal charged particles repel each other), Brownian motion (random movement) and van der Waals forces (attraction/repulsion between molecules due to dipoles).

The ordering of particles inside the wedge structure can occur because the overall entropy of the dispersion increases as the nanoparticles in the bulk liquid achieve greater freedom. The electrostatic repulsion between the particles will be higher for particles with smaller size, giving a larger structural disjoining pressure. Also, when the amount of particles increases, the force working on the wedge film will increase [18].Wasan and Nikolov (2003) showed that the spreading behavior increased with decreasing the film thickness, that is, the number of particle layers in the film [16].

When the structural disjoining pressure works on the vertex of the discontinuous phase, displacement occurs as the system tries to regain equilibrium. This force is related to the nano fluids ability to spread out on the surface of the rock due to imbalance of the interfacial forces between oil phase, aqueous phase and solid. The magnitude of this pressure depends on parameters such as particle size, particle volume fraction, polydispersity, temperature, and salinity and rock properties. (Wasan and Nikolov, 2003; Zhang et al., 2014) Adding more electrolytes to the aqueous nano fluid will lower the disjoining pressure. Increasing salt concentration will lower the repulsive forces between nanoparticles and hence reduce the pressure that drives the wedge film. Because of this, an increase in salinity will have a negative effect on oil removal in the case of nano fluids $[16,19]$.

\subsection{Effect on Interfacial Tension}

Oil and water are immiscible fluids, which mean that the interfacial tension (IFT) between them is high. Introducing silica hydrophilic nanoparticles to the system has been observed to lower the IFT and potentially produce more oil. The nanoparticles will structure themselves at the oil/brine interface, reducing the contact between the two phases. The layer of particles generates a lower IFT between which phases, much like surfactants works. The IFT tension is sensitive to nano fluid concentration; as the concentration increases, IFT decreases. (Li et al., 2013a; Dahle, 2013)

In this thesis hydrophilic silica is used to reduce oil/water IFT, but also neutral wetting particles would have an effect [20]. Frijters et al. (2012) explained how the mechanisms behind the adsorption of neutral we particles works, and compares with surfactants. Surfactants adsorb at the interface due to their hydrophilic head and hydrophobic tail while neutral wetting nanoparticles adsorb because maintaining a particle-fluid interface requires less energy. Neutral wetting nanoparticles were reported to change the interfacial free energy by taking away energetically expensive fluid-fluid interfaces and replace them with a cheaper particle-fluid interface. This can be shown by the free energy term $F_{\sigma}$ as a function of surface tension and droplet area (Frijters et al., 2012):

$\mathrm{F} \sigma=\int_{\delta A} \sigma \delta A$

The reduction of the interfacial free energy requires either (i) reduction of interfacial tension $\sigma$, which is achieved with adding surfactants, or (ii) reduce the area of integration, which is the effect of adsorbed particles. This shows that neutral wetting nanoparticles can reduce the overall interfacial free energy not by reducing the IFT itself, but by removing parts of the energetically unfavorable fluidfluid interface area. For emulsions, assembly of particles on the oil droplet's surface is favorable because it blocks for destabilization by Ostwald ripening (larger droplets grows at the expense of small ones). It can also break up oil droplets (see Figure-3), making it easier for the emulsion to migrate through the porous media[21].

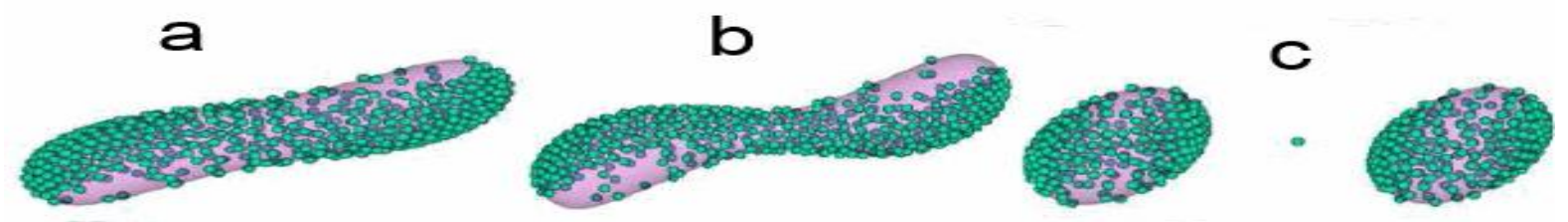

Figure3. Breakup of oil droplets due to adsorption of nanoparticles [21] 


\section{Materials ANd Methodology in Enhanced OIL Recovery}

\subsection{Fluids Preparation}

The formation water obtained from the reservoir where the core sample was recovered has a salinity of 30000ppm. The brine used for this experiment was prepared in the laboratory with the same salinity as reservoir formation water. The compositions of brine are shown in table 1 . To ensure that all the salts were fully dissolved, a magnetic pin was used to stir the solution for 4-6 hours. Two different types of nano particles were used. The first one was nano carbon particles (of size about less than $10 \mathrm{~nm}$ ) which are a combination that show suspension stability due to unique structure. Another type of nanoparticles used in this research is named $\mathrm{Sio}_{2}$ (10-20 nm, purity: $98-99.5 \%$ and specific area $160 \mathrm{~m}^{2} / \mathrm{gr}$ ). $50 \mathrm{mg}$ of $\mathrm{SiO}_{2} \mathrm{NPs}$ and $0.05 \mathrm{wt} \%$ of nano carbon in were dispersed in 1 liter of DIW to make nano fluid suspensions. DIW was selected as dispersion phase in this research. The suspensions were stirred for an hour using a shaker at ranging 220-250 rpm and ultrasonicated by an ultrasonic bath for a period of $1 \mathrm{~h}$ to achieve homogeneous suspensions before each test. The suspensions were prepared $30 \mathrm{~min}$ before introduction to porous media. These suspensions were prepared as mentioned in table 2 .

Table1. Composition of brine

\begin{tabular}{|c|c|c|}
\hline Salt & Mass g/L & Concentration wt\% \\
\hline $\mathrm{NaCl}$ & 30 & 2.91 \\
\hline $\mathrm{KCl}$ & 0.25 & 0.02 \\
\hline $\mathrm{Na}_{2} \mathrm{SO}_{4}$ & 1.02 & 0.1 \\
\hline $\mathrm{NaHCO}_{3}$ & 0.2 & 0.019 \\
\hline Total & 31.47 & 3.05 \\
\hline
\end{tabular}

Table2. Weight percent nano particles in suspensions

\begin{tabular}{|c|c|c|}
\hline Weight Percentage, $\%$ & Nano particles, gr. & Water, ml. \\
\hline 0.05 & $\mathrm{SiO}_{2}-50$ & 99.85 \\
\hline 0.05 & nano carbon- 50 & 99.85 \\
\hline
\end{tabular}

\subsection{Porous Media}

The core flooding tests were done under partial reservoir conditions. A confining pressure of $1500 \mathrm{psi}$ was used at room temperature. Some natural core plugs used for this study are water wet sand stone rock obtained from an oil field in south part of Iran. Each plug is experimented with a light crude oil with API gravity ranges of 40-44o. The average porosity of these cores varies from $17.02 \%$ to 21 . The permeability of the cores is ranging from 285 to $725 \mathrm{mD}$ according to the ASTM D2434-68 method [22].

\section{EXPERIMENTAL}

\subsection{Contact Angle Measurement}

The contact angle of an oil droplet on small slices surface of core plug in order to investigate how nanoparticles affect the wettability. Torun contact angle tests, the core plugs are cut in small pieces of $1 \mathrm{~cm}$ in diameter and $0.4 \mathrm{~cm}$ thickness by using a trimming machine and polished to obtain a flat and smooth surface.

The slices were aged in formation water for three weeks and then positioned vertically in crude oil for two weeks to create oil-wet conditions. Next, oil-wet calcite slices were washed with toluene and dried in hot oven in $50^{\circ} \mathrm{C}$ for 24 hours. For measuring the initial wettability of slices, the contact angle tests were run with the pendant dropdevice. The experiment was conducted at ambient conditions. To investigate the effectiveness of nanoparticles on the wettability alteration different suspensions of nano particles including carbon nano particles and $\mathrm{SiO}_{2}$ were introduced to the slices. A scanning electron microscope indicated that the particles have potential to alter the wettability of a reservoir rock. An increase in contact angle compared to brine means that the surface has become more water wet. 


\subsection{Core flooding experiment}

All of the cores were fully saturated with the formation water in a vacuum container for several days to allow equilibration with rock constituents at room temperature and a low pressure of $100 \mathrm{mbar}$. The drainage process was initiated by injection of a crude oil that achieved from a field in the Iran in this research. A constant pump rate of $0.1 \mathrm{~mL} / \mathrm{min}$ for both brine and nano fluid were used. First brine was injected to displace oil until residual oil saturation was reached. Afterwards, nano fluids were used as a tertiary recovery method to see if any additional oil could be mobilized. Each phase was continued until no more oil was produced, usually after 2-3 PV injected. Nanofluid including $\mathrm{Sio}_{2}$ was used in this experiment because of the same efficiency with carbon nano fluid in the wettability alteration of core plug at this concentration. Water flooding recovery of a coreplug was about $60 \%$ and, by the injection of nanofluid, oil recovery increased by $5 \%$ as a tertiary process. As shown in Figure 5, the result indicates that Silica nanoparticles can increase oil recovery.

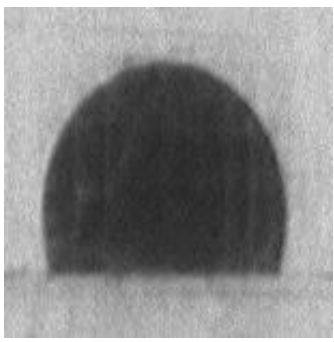

a.Brine

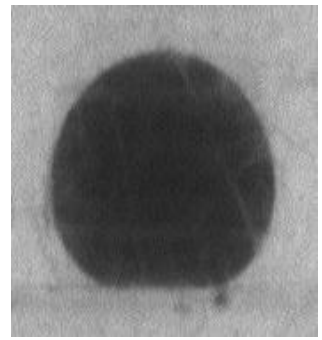

b. carbon nano particles

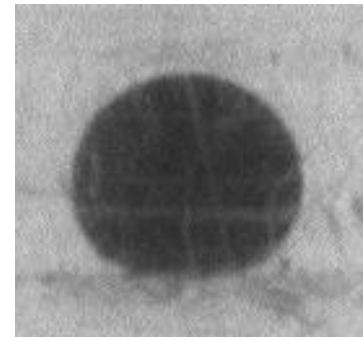

c. $\mathrm{SiO}_{2}$

Figure4. Contact angle test results with different type of fluids.

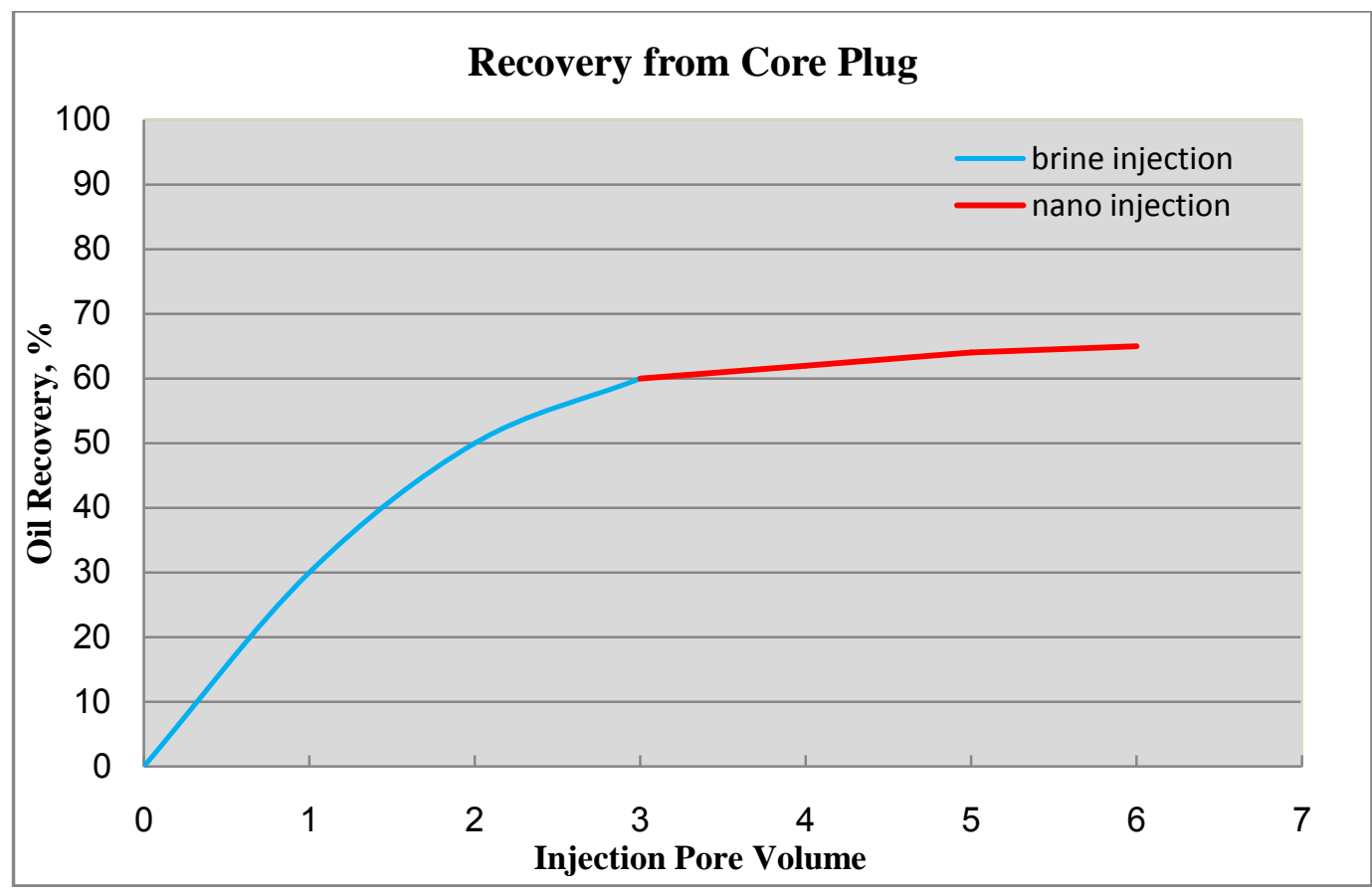

Figure5. Oil recovery results for water flooding and nano fluid injection

\section{Conclusion}

This paper presents the effect of two types of nano particles including silica nano and Carbon nano particles through a core plug sample on improving oil recovery efficiency through a core plug sampleof the Iran reservoir. For this aim, several core flooding experiments and contact angle tests were carried out to investigate the potential of these particles in altering the wettability. Based on these experiments, the following conclusions can be obtained:

- nanoparticles can be considered as an effective agent in the changing the wettability of carbonate rock surface from oil-wet to water-wet,

- By injecting nanofluid as a tertiary recovery, oil recovery increased by 5\%through changing the wettability of rock surface. 


\section{REFERENCES}

[1] US Energy Information Administration, 2011. International energy outlook 2011. Washington DC: US Energy Information Administration.

[2] HadiShamsiJazeyi, Clarence A. Miller, Michael S. Wong, James M. Tour, Rafael Verduzco," Polymer-Coated Nanoparticles for Enhanced Oil Recovery", applied polymer science journal, 2014.

[3] Opening Remarks by HSE Abdalla S. El-Badri, OPEC Secretary General, to the International Energy Week. 2013. Moscow, Russia.

[4] Khanam Mehwish. 2014. Nanotechnology-A wind of change in oil and gas industry. Young Petro.

[5] M. Kong, M.M. Ohadi, $(Y \cdot 1 \cdot)$. Application of micro and Nano technologies in the oil and gas industry an overview of recent progress.Abu Dhabi international Petroleum Exhibition \&conference, Abu Dhabi, USE.

[6] Song, Y.Q, and Marcus, C. Y.. V. Hyperpolarized Silicon Nanoparticles: Reinventing Oil Exploration Presentation.

[7] Kanj, M.Y. (Editor) (2008): "Nanotechnology in Upstream E\&P: Nano-Scale Revolutions to Mega-Scale Challenges?" SPE Applied Technology Workshop Report, Dubai, U.A.E., February 3-6.

[8] Kanj, M.Y., Funk, J.J., and Afaleg, N.I. (2008): "Towards In-situ Reservoir Nano-Agents," Proceeding of the NSTI Nanotechnology Conference and Trade Show, Boston, MA, June 1-5.

[9] Kanj, M.Y., Funk, J.J., and Al-Yousif, Z. (2009): "Nanofluid Coreflood Experiments in the Arab-D," SPE\#126161 presented at the SPE Saudi Arabia Technical Symposium and Exhibition, al-Khobar, Saudi Arabia, May 09-11.

[10] Hendraningrat, L.; Li, S.; Torsæter, O. A core flood investigation of nanofluid enhanced oil recovery.J. Pet. Sci. Eng. 2013, 111, 128- 138.

[11] Zhang, Y.; Chen, Y.; Westerhoff, P.; Crittenden, J. Impact of natural organic matter and divalent cations on the stability of aqueous nanoparticles. Water Res. 2009, 43, 4249-4257.

[12] Ju, B.; Fan, T.; Ma, M. Enhanced Oil Recovery by flooding with Hydrophilic Nanoparticles. China Particuol.2006, 4 (1), 41-46.

[13] Mokhatab, S., Fresky, M.A., Islam, M.R.: Application of Nanotechnology in Oil and Gas E\&P. JPT, Society of Petroleum Engineers (2006).

[14] Li, S., Hendraningrat, L., and Torsaeter, O. Improved oil recovery by hydrophilic Silica nanoparticles suspension: 2-phase flow experimental studies. 2013a.

[15] Nanowerk. Introduction to nanotechnology. URL www.nanowerk.com/ nanotechnology/introduction/.

[16] Wasan, D. T. and Nikolov, A. D. Spreading of nano fluids on solids. Nature, 423(6936):156 $\{159,2003$. ISSN 0028-0836.

[17] Chengara, A., Nikolov, A. D., Wasan, D. T., Trokhymchuk, A., and Henderson, D. Spreading of nano fluids driven by the structural disjoining pressure gradient. Journal of Colloid and Interface Science, 280:192\{201, 2004.ISSN 0021-9797.

[18] Wasan, D., Nikolov, A., and Kondiparty, K. The wetting and spreading of nano fluids on solids: Role of the structural disjoining pressure. Current Opinion in Colloid and Interface Science, 16(4):344\{349, 2011.

[19] Zhang, H., Nikolov, A., and Wasan, D. Enhanced oil recovery (eor) using nanoparticle dispersions: Underlying mechanism and imbibitions experiments. 2014.

[20] Dahle, G. S. The Effect of Nanoparticles on Oil/Water Interfacial Tension. Project thesis, NTNU, 2013.

[21] Frijters, S., Gunther, F., and Harting, J. Effects of nanoparticles and surfactant on droplets in shear flow. 2012. doi: 10.1039/C2SM25209K.

[22] ASTM Standard D2434-68, 2006, Standard Test Method for Permeability of Granular Soils (Constant Head); ASTM International, West Conshohocken, PA, 2006; DOI: 10.1520/D243468R06, www. astm.org. 